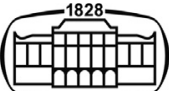

AKADÉMIAI KIADÓ

International Review of Applied Sciences and Engineering

$11(2020)$ 3, 261-268

DOI:

$10.1556 / 1848.2020 .00096$

(c) 2020 The Author(s)

\section{ORIGINAL RESEARCH} PAPER

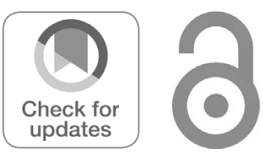

\title{
Development equipment for hydro-jet forming of women designer's headwear
}

\section{OLENA YAKYMCHUK ${ }^{1} \odot$, DMYTRO YAKYMCHUK ${ }^{2 *} \odot$, NATALIIA BILEI-RUBAN ${ }^{3} \odot$, IRYNA NOSOVA ${ }^{2} \odot$, SERHIY HORIASHCHENKO ${ }^{4} \odot$, KOSTYANTYN HORIASHCHENKO ${ }^{5} \odot$, TETYANA KISIL ${ }^{6} \odot$ and VIACHESLAV TUZ ${ }^{6} \odot$}

\footnotetext{
${ }^{1}$ Department of Design, Kherson National Technical University, Kherson 73008, Ukraine

${ }^{2}$ Department of Hotel-Restaurant and Tourism Business, Kherson State University, Kherson 73000, Ukraine

${ }^{3}$ Department of Light Industry and Professional Education, Mukachevo State University, Mukachevo 89600, Ukraine

${ }^{4}$ Department of Machines and Apparatuses, Electromechanical and Power Systems, Khmelnytskyi National University, Khmelnytskyi 29016, Ukraine

${ }^{5}$ Department of Telecommunications and Computer Integrated Technologies, Khmelnytskyi National University, Khmelnytskyi 29016, Ukraine

${ }^{6}$ Department of Instrumentation, Mechatronics and Computerized Technologies, Cherkasy State Technological University, Cherkasy 18006, Ukraine
}

Received: January 24, 2020 • Accepted: May 13, 2020

Published online: October 20, 2020

\begin{abstract}
The objective of this research is to develop the equipment for liquid-jet forming of women's headwear hats, which will allow expanding design assortment of these products. The equipment for cyclic liquidjet forming of headwear hats in liquid-active working environment (LAWE) with forming element rotation was designed. The mechanism of movement and orientation of liquid -jet forming nozzle was developed, which allows influencing fabric parts by flooded and controlled liquid-jet, repeating the contour at a certain distance and with appropriate angle attack on each technological section of the part. The conducted experimental research allowed to receive semi-spherical forms of headwear hats from six fabrics suit-coat assortments, which are one of the most difficult forms of non-seam forming. Completely formed hats of a given complex configuration were obtained by liquid-jet forming, different from standard semi-spherical ones. The developed equipment provides mobility of the production from the point of view of quick equipment adaptation due to action use of flooded controlled liquid-jet and forming of a significant number of various hats contours, various combinations of technological forming modes.
\end{abstract}

\section{KEYWORDS}

liquid-active working environment, hydro-jet forming, headwear hats, flooded hydro-jet, jet forming nozzle

\section{INTRODUCTION}

*Corresponding author

E-mail: starcon84@gmail.com

Today energy saving plays a key role in the development of all industries. A constant increase in the cost of energy resources forces the state to develop new technologies and equipment, which would correspond to modern requirements of energy efficiency.

This factor also applies to the light industry and other industries. Modern market conditions with high competition require constant introduction of modern energy saving 
technologies and in establishments of economy. This industry is important for any state, since it provides up to $30 \%$ of gross domestic product.

Design sector is characterized by similar energy saving tendencies. The clothing design, taking into account energy saving factor, is devoted to many works today. However, such significant component of image like a headdress remains poorly investigated in the context of designing image, with respect to the main technological aspects of its implementation. Mobile response on fashion and technological trends in order to attract a significant number of customers is typical for different hospitality establishments. Therefore, a figurative solution of the staff image as external look of the persons requires a rapid reaction of designer and technologist to the market needs of attractive economic objects. As for the manufacture of headwear, which is an integral part of worker clothes, then a lot of attention in this perspective is devoted to the seamless forming of their volume and spatial parts (hats). Development of new technologies and equipment for their implementation will allow to save materials, energy and labor resources to a large extent. This will reduce a number of fabric loss when cutting. The technological chain will be simplified, excluding a number of operations and use of excess energy at the thermal treatment parts in a constructive forming.

One of the latest alternative ways of seamless forming of volumetric parts of headwear from fabrics is liquid-jet forming. But realization of this idea requires development of certain special equipment to provide optimal conditions of technological process and obtaining a product of high quality and competitive design. Therefore, the study of existing hydro-jet technology in other areas is a necessary stage of work on the way of designing special equipment for headwear hydro-jet forming.

Equipment applying the technology of hydro-jet forming has been widely used in many industries. The use of a hydro jet as an element when cutting various materials is known [1]. At the same time, due to high pressure a water jet provides a guaranteed cutting of solid materials to a fixed value. However, the indicated equipment has a narrow direction and cannot be used for other purposes.

Hydro-jet technologies become widespread when removing rust of the inner walls of steel tubes [2]. With the help of abrasive jet there is a guaranteed rust removal of considerable size, which significantly increases the life of tubes and reduces the cost of their manufacturing. However, this technology has not been widely disseminated due to a number of significant disadvantages.

In industry equipment for pre-treatment of surfaces is used with a stream of water with addition of abrasive particles [3]. This allows to improve the quality of surfaces by processing of abrasive particles, which is conducted at the expense of using high pressure jet. It penetrates into all microniveness and provides formation of a practically perfectly treated surface. It should be noted that the described equipment is energy-intensive and has a high cost. This narrows down the use in various industries.

A known equipment for cutting materials [4] is based on a low pressure water jet cutter. Such equipment has advantages and disadvantages, however, it does not provide guaranteed cutting of materials of a large thickness and has a narrow functional application.

The mechanism of accelerated destruction of abrasive particles was investigated and a system of cutting materials by compressed abrasive jet was developed [5]. But, the developed technology is experimental and cannot be used as industrial equipment. Also, the influence of abrasive particles on material is investigated only in terms of interaction with a latter in context of cutting. This does not give an idea of a possible positive effect of water jet on different samples.

A study of characteristics of abrasive water jets is also studied by simulation in specialized software package CFD [6]. A study of process is described using various factors, and simulation is provided using the CFD complex. However, hydro jets are investigated only under fixed conditions, which does not give an objective idea of the spectrum of use.

Consequently, as analysis result determined that for today there is no match equipment in fact for hydro-jet forming of headwear volumetric details, especially in designing women's suits. The main task of existing modern liquid-jet technologies is mainly directed at the destruction of materials by liquid-jets of super high pressure. Therefore, development of the equipment for liquid-jet seamless forming is a topical task, which will allow plasticizing of fabric and forming it at the same time by more cautious action of flooded liquid-jet.

\section{MATERIALS AND METHODS}

\subsection{Influence of working environment on fabric structure}

In a process of formation, working environment is in contact with the textile material. It changes its properties - plasticizes and promotes the "transition" from glass-like state to highly elastic or glutinous fluid. The main factors of work environment are heat, moisture and mechanical action [7, 8].

Dependence of polymer deformation on temperature and determination of temperature interval of wet heat processing (WHP) is determined by a thermomechanical curve. The shape of thermomechanical curves of various textile materials is very close to thermomechanical curve of amorphous polymer.

Processes occurring on a surface and inside of textile fibers (wetting, steam sorption, swelling, dissolution, chemical destruction) are described by thermodynamic and molecular-kinetic positions and depend on the structure of the fiber itself $[7,9]$. A presence in fibers macromolecules of strongly polar hydrophilic groups $\left(\mathrm{OH}, \mathrm{NH}_{2}, \mathrm{COOH}\right.$, $\mathrm{CONH}$ ) creates a significant force field that attracts and retains water molecules [10-13]. That is why cellulose (cotton, flax, viscose) and fiber (silk, wool) fibers have a high ability to absorb water vapor.

At a close contact with water, it is absorbed by sorption and mechanically (capillary) due to the structure of the material [7, 14, 15]. Hygroscopic absorption occurs at 
physical-chemical bond of moisture from amorphous regions of molecular chains. The moisture, which fills the capillaries, pores and intervals between threads is less connected than at the physical-chemical bond [7, 14, 15].

\subsection{Analysis of existing headwear forming technologies}

As a material we used six fabrics of suit-coat assortment. Fabrics with different characteristics are selected considering possible changes when forming.

It is known that the quality of the formed part depends not only on the amount of moisture, which is used, but also on its state (steam or liquid).

Lately, as a working environment, instead of using a steam-air mixture, a liquid-active working environment (LAWE) is recommended. This is the environment for the formation of textile materials, which is based on water. It is used for plasticization of material and transfer of mechanical effort. Compared with a steam-air mixture, LAWE use has the following advantages [16]:

- performs coolant functions;

- uses as lubricant, which reduces a coefficient of friction between threads systems;
- activates a "rough" structure and provides change in the angles between thread systems;

- allows to transfer the "rough" structure of glue particles in colloidal state.

Increased deformation properties of fabrics are achieved due to their maximum moisture content: when using vapor - 20\%, sometimes - 60\%; when using LAWE - 78\%.

Mainly, a significant deformation of a textile materials is happening in the initial period of application load. Then the deformation gradually goes out and it stops, state of equilibrium is appearing. The deformation of a textile material, which is being determined at this moment, indicates the total value of absolute deformation. It consists of resilient, elastic and plastic deformation, that influences the process of headwear forming [17-20].

The application of high temperatures is not always appropriate in terms of energy intensity of the forming process of clothing parts and headgear. Therefore, development of new methods and forming technology as an alternative catalyst temperature of process mechanical load can be applied, attached to the material which is formed. Analysis results of direction and mechanical loads magnitude and strengths of work environment on textile material $[21,22]$ are shown in Fig. 1.

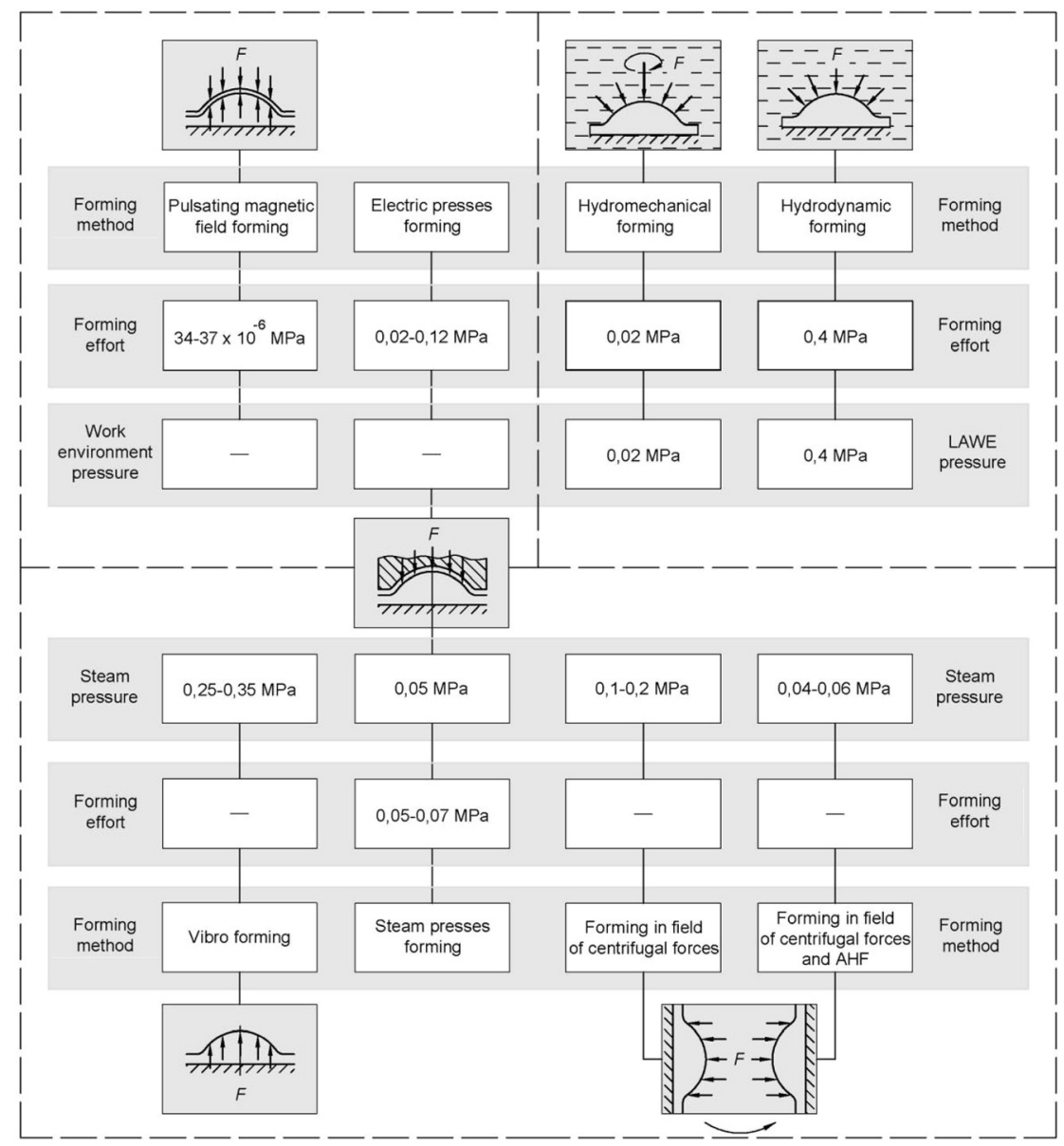

Fig. 1. Scheme of loads action for different forming types 
To analyze existing forming processes from the aspect of forming effort and specific action of working environment eight technologies that are known today and equipment for their realization were selected (Fig. 1). As a working environment in investigated technologies a steam use is predominant (in 6 of 8 cases) and to a lesser extent - LAWE (in 2 of 8 cases).

According to the conducted research it was determined that when forming steam is used with the pressure of $0.04-$ $0.5 \mathrm{MPa}$, compressed air - 0.2-0.5 MPa, LAWE - 0.4 MPa; a range of molding loads is from 0.02 to $0.12 \mathrm{MPa}$. Therefore, when developing a new method of forming a work environment with a pressure of $0.04-0.5 \mathrm{MPa}$ and the specific forming load 0.02-0.12 $\mathrm{MPa}$ can be used.

\subsection{Advantages of using LAWE technology}

Based on the above, using LAWE technology has the following advantages:

- reduction of friction coefficient between systems of threads;

- promoting the change of angles between systems of threads;

- the mobility of the "rough" structure;

- fabric plasticization;

- transfer of forming load to a part, which greatly enhances deformation properties of fabric.

Thus, equipment for liquid-jet forming of headwear volumetric details in designing of women's suit was analyzed. The features of process pass with different types of forming and prospects of LAWE using were determined.

The purpose of work is equipment development for hydro-jet seamless forming of women's headwear hats, which will allow to expand design assortment of these products.

To achieve the proposed goal, the following tasks were set:

- developing equipment for hydro-jet forming of headwear hats;

- developing a movement and orientation mechanism of jet forming nozzle;

- conducting experimental research of headwear details forming of semi-spherical shape;

- conducting experimental research of headwear details forming of difficult spatial non-standard form.

\section{RESULTS AND DISCUSSION}

To expand the technological capabilities of headwear details forming from fabrics an experimental equipment was prepared, which allows to simulate a process of hydro-jet forming. This equipment has a jet-forming nozzle, moving at a given distance and at a certain angle to a surface of semifinished product in front of a cross-sectional area of perforated molding element and repeats its semi-circle. A forming element is located on the sample stage, which is fixed on a shaft that is rotating around its axis. A working camera filled up with LAWE, which plasticizes fabric parts and forms a surface layer, by flooded liquid-jet.

\subsection{Development of experimental equipment}

Developed experimental equipment for hydro-jet forming of headwear details consist of the following parts: clamping ring; forming element; working camera; subject table; shaft; sleeves; LAWE tank; vibration pump for LAWE feed; jet forming nozzle; engine drive; pump for LAWE pulling out; tachometer; system of displacement and orientation of a nozzle; LAWE pressure control unit; control unit for shaft rotation speed with a part; PC; power supply unit microcontroller.

The semi-finished product was fixed by means of clamping rings on perforated forming element, located in working camera on subject table. Object table was fixed on shaft, rotating in sleeves at expense of drive. LAWE from a tank with a vibro pump comes in jet forming nozzle. For water pulling out from working camera a pump used.

The experimental equipment for forming headwear parts by hydro-jet method works as follows.

A certain amount of LAWE is sent into the working camera from tank for pre-plasticization of semi-finished fabric. Due to the work of vibration pump and using a jet nozzle a flooded hydro-jet is formed. The hydro-jet action on semi-finished product is the main condition of this method of headwear details forming. Shaft gets rotary movements from drive. A perforated forming element rotates together with a shaft at a speed, which is set in a range from 60 to $300 \mathrm{rpm}$.

Upon completion of the hydro-jet forming process LAWE is removed from working camera using pump into a reservoir and drying a part of resulting form (Fig. 2).

\subsection{Development mechanism of movement and orientation of jet forming nozzle}

CNHM movement is provided by moving toothed pass which is clamped in bracket carriage and is between tensioning device and a gear, planted on a stepper motor shaft.

Fig. 3 shows a kinematic scheme movement and orientation mechanism of jet forming injector (nozzle). A carriage moves by the rails which supports from other side (Fig. 4a).

On a carriage of nozzle of horizontal movement is fixed a carriage of nozzle of vertical movement. It moves as follows. Engine rotation is transferred to carriage at expense of couple work screw-nut and G-shaped bracket (Fig. 4b).

\subsection{Development mechanism of nozzle holder}

In a holder jet forming nozzle is inserted to the end into a control washer in such way that its end is located on one axis with centering suspension (Fig. 5).

The research conducted shows that the equipment developed for hydro-jet forming of headwear details has some advantages. Due to the application of jet forming 


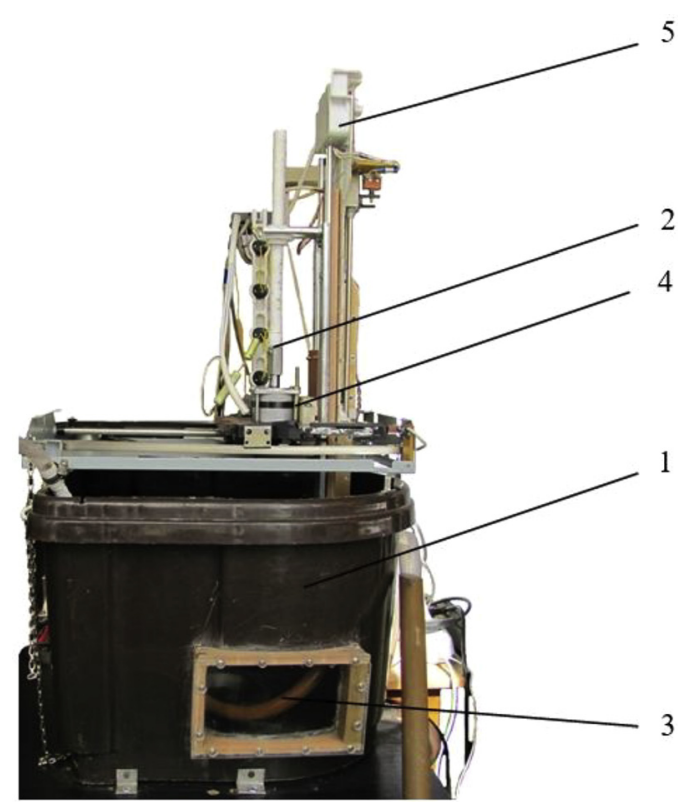

Fig. 2. Experimental equipment for hydro-jet forming headwear volumetric details 1 - working camera, 2 - nozzle orientation node, 3 - overview window, 4 - stepper motor, 5 - vertical axe direction

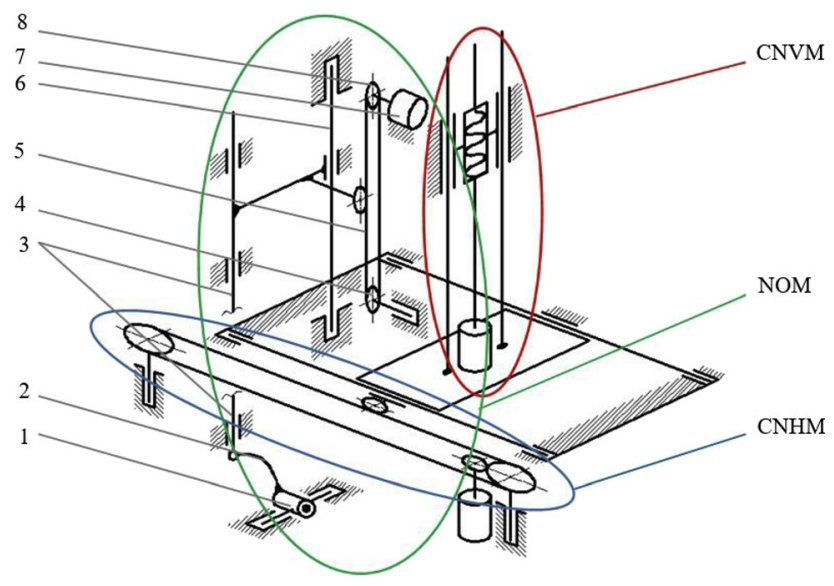

Fig. 3. Kinematic scheme movement and orientation mechanism of jet forming nozzle of experimental equipment for hydro-jet forming CNVM - carriage of nozzle vertical movement, NOM - nozzle orientation mode, CNHM - carriage of nozzle horizontal movement, 1 - nozzle holder, 2 - sickle traction, 3 - slider, 4 - tensile device, 5 - toothed belt, 6 - guide link, 7 - stepper motor, 8 - stepper motor gear

nozzle good forming parts of products was realized. This was achieved by creating concentrated pressure of nozzle on detail surface and moving at a certain distance from it and at a given angle of attack in accordance with a contour of forming element (Fig. 6).

\subsection{Formation features of headwear in LAWE environment}

An illustration of an immersion process of flooded hydro-jet in LAWE with a part, which is in it and fixed on the forming
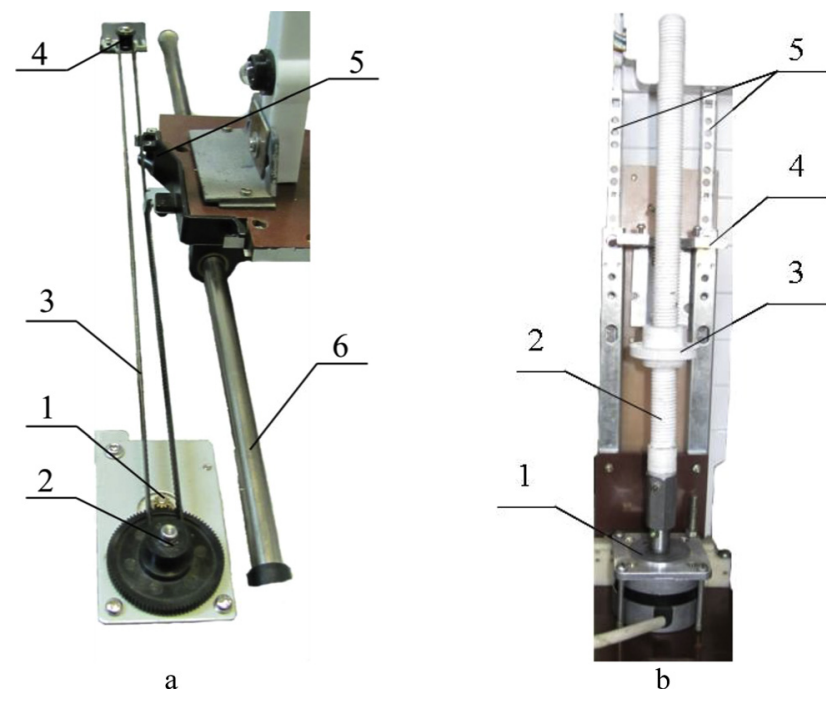

Fig. 4. Movement and orientation mechanisms of nozzle a - carriage of nozzle horizontal movement, 1 - stepper motor, 2 - stepper motor gear, 3 - toothed pass, 4 - tightener, 5 - carriage bracket of horizontal movement, 6 - guide link, b - carriage of nozzle vertical movement, 1 - stepper motor, 2 - screw, 3 - nut, 4 - G-shaped bracket carriage of nozzle vertical movement, 5 - guide links

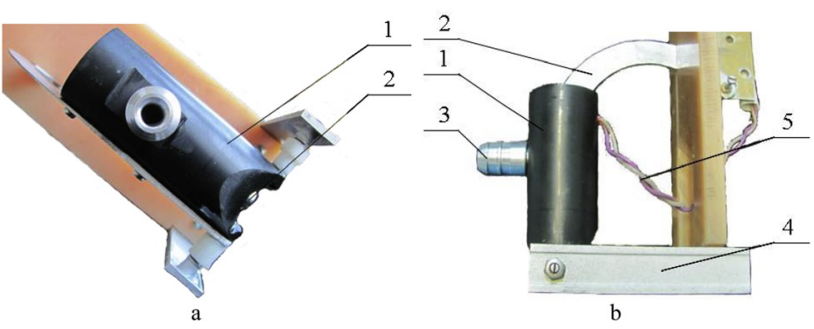

Fig. 5. Nozzle holder a - frontal image, 1 - nozzle holder, 2 nozzle, $\mathrm{b}$ - side view, 1 - nozzle holder, 2 - sickle traction, 3 fitting, 4 - nozzle centering suspension, 5 - LED connecting wire

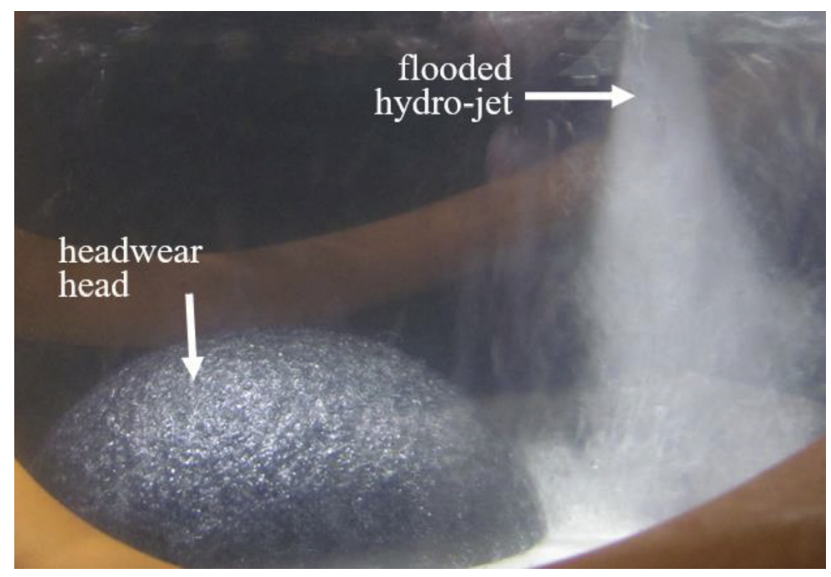

Fig. 6. Hydro-jet immersion in LAWE before forming headwear detail 
element, is shown in Fig. 6. At the moment, detail is shown before giving a turn. The flooded hydro-jet is at starting point and has not come close at required distance to detail. Inclination angle of jet forming nozzle axle relative to plane of detail is also in starting position and is $90^{\circ}$.

A distinctive feature of the developed equipment use for hydro-jet forming of headwear hats is the possibility of applying LAWE as a working environment for better fabric plasticization. The second positive aspect is providing action of controlled flooded hydro-jet, which repeats contour of detail which is formed. Besides, the end of jet forming nozzle has the ability to move at a given distance and under a certain angle of nozzle axis to detail plane which is formed. The result is a varying possibility of a wide range of forming technological parameters depending on structural and geometric fabrics characteristics of studied details. It allows for experimenting not only with a wide range of materials, but also for exploring (performing) hydro-jet forming of headwear hats, contours of different desirable curvature. This aspect will expand the variation range of women's headwear design-forms, made from fabrics. A successful engineering solution for hydro-jet forming equipment is an idea of giving a rotary motion of molding element with fixed detail on it. This adds dynamics to formation process and catalyzes it.

The main effect of the proposed solution is the transformation of local action character flooded hydro-jet in a frontal and cover with generated force field of whole parts area of headwear during formation. Another positive moment of the developed equipment is the sufficient effect of flooded hydro-jet and rotation of a headwear part for forming without the application of additional LAWE heating. This makes it possible to make the forming process considerably cheaper without applying excessive expenses for heating LAWE.

The equipment for hydro-jet forming of headwear hats was developed based on the concept of cyclic forming process. That is, after forming is finished, LAWE is sucked into the reservoir, from which it is repeatedly reused. Next it goes to molding camera and takes part in further processes of hydro-jet forming following headwear details. This fact also allows to significantly reduce the cost of using resources.

The developed equipment has specific technological parameters.

A suit and coat fabrics with the following sizes are used as materials for headgear hats: head diameter $D_{\mathrm{o}}-58-60$ $\mathrm{cm}$; head height $H_{o}-9-11 \mathrm{~cm}$. The mechanism of fixation of obtained forms is press ring, which presses the material into a shape. This is a simple and reliable way of fixing the material during forming.

Optimal parameters of hydro-jet forming of headwear hats are determined:

- for coat fabrics (pressure $P_{d}=0.04 \mathrm{MPa}$, forming time $t=115-159$ s., rotation speed $n=180 \mathrm{rpm}$ );

- for suit fabrics (pressure $P_{d}=0.03-0.05 \mathrm{MPa}$, forming time $t=98$ s., rotation speed $n=116-157 \mathrm{rpm}$ ).

Developed equipment and the forming element of new configuration allowed to use obtained results when forming headwear hats of difficult spatial shape from the fabrics of suit-coat assortment.

Application of hydro-jet technology of headwear details forming from a woolen fabric of suit-coat assortment allows to reduce a construction period design. And also the forming of female headwear hat due to intensification of the process using a controlled flooded hydro-jet. Such hydro-jet automatically reproduces desired detail contour.

The developed technology provides production mobility from positions of equipment rapid adaptation to introduction of a new range of products through the use of special equipment. Specified equipment provides forming of considerable quantity of various hats contours and various combinations of technological forming modes. This allows to expand the creative possibilities of women's headwear designers.

\subsection{Formation of semi-spherical and difficult spatial forms}

In the experiment semi-spherical (standard) forms of headwear hats from six fabrics of a suit-coat assortment were received. Two of them are shown in Fig. 7. Receiving non-constructive way of completely formed parts of such form is a difficult task. It was solved by applying the capabilities of the developed equipment for hydro-jet forming of volumetric headwear details.

The next step was getting a form of and entirely formed hat of given complex configuration, different from a standard semi-spherical by using hydro-jet forming. On the developed equipment different hat configurations from six fabrics of a suit-coat assortment were received, two of which are shown in Fig. 8.

The developed equipment has several disadvantages. It is not perfect in terms of reliability, because it is experimental. To improve reliability, an industrial sample must be

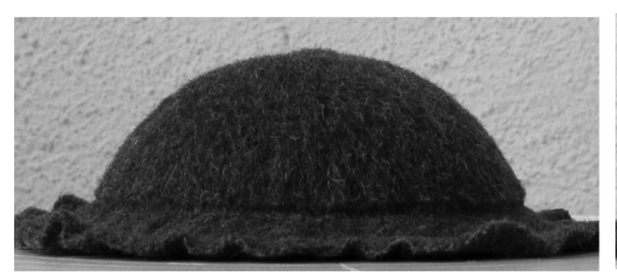

a

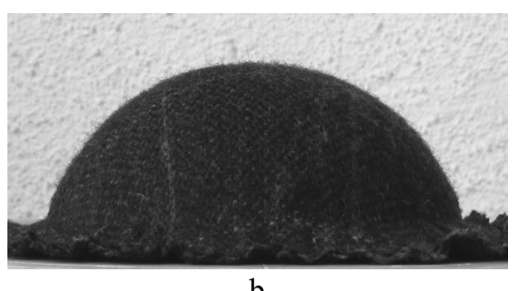

b

Fig. 7. Picture of semi-spherical headwear details from fabrics of a suit-coat assortment 


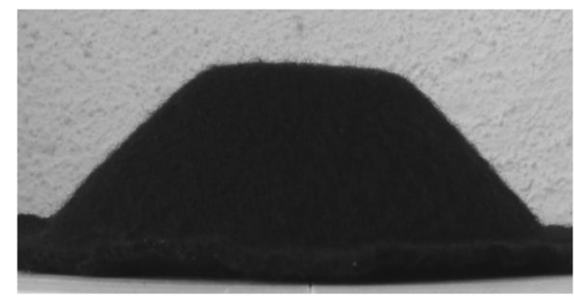

a

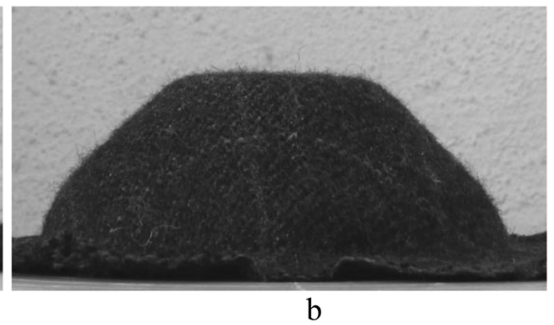

Fig. 8. Hat image of difficult spatial form, formed by hydro-jet method from fabrics of a suit-coat assortment

developed. Also, to expand technological opportunities it is necessary to increase the assortment of fabrics and conduct additional experiments with them. This will allow to judge with greater certainty what the advantages and disadvantages of the developed equipment are. It should be noted that it is necessary to increase forms variety of headwears hats. In addition, the influence of movement and orientation mechanism of jet forming nozzle on characteristics of final product has to be studied to a greater extent.

Despite the above disadvantages, the developed equipment provides production mobility from the point of view of rapid equipment adaptation due to action use of flooded controlled hydro-jet. The specified equipment provides forming a significant number of various hat contours and various combinations of technological forming modes. This allows to expand the creative possibilities of women's headwears designers.

\section{CONCLUSION}

In this study an equipment was developed for cyclic hydrojet forming of headwear hats in LAWE with forming element rotation around its axis with fixed detail on it. The developed mechanism of moving and orientation of hydro-jet forming nozzle which allows to influence fabric parts of flooded controlled hydro-jet, repeating contour at a certain distance and with appropriate angle attack on each technological detail section. Semi-spherical forms of headwears hats from six fabrics suit-coat assortment were received, which are one of the most difficult forms of non-seam forming on the developed equipment. By using hydro-jet forming on the experimental equipment entirely formed hats given complex configuration, different from standard semi-spherical were received. The developed equipment provides production mobility from the point of view of rapid equipment adaptation due to action use of flooded controlled hydro-jet and forming a significant number of various hat contours, various combinations of technological forming modes.

\section{REFERENCES}

[1] J. Sun, Water-Jet Cutting Technology, vol. 2, Xuzhou, China University of Mining and Technology Press, 1992, p. 12.
[2] Z. Dongsu, L. Lihong, and X. Xiaoshi, "Experiment research on rust removal of inner wall of steel tube by use of abrasive jet," Min. Process. Equip., vol. 4, pp. 39-40, 2002.

[3] L. Lihong, L. Zhanni, C. Hanbing, and L. Benli, "Abrasive jet surface pretreatment equipment," Mater. Renew. Energy Environ. (ICMREE), vol. 1, pp. 44-56, 2011.

[4] Z. Dongsu, D. Zuwei, C. Bin, and Y. Lizhi, "Development of lower pressure water jet cutter," Int. Conf. Eng. Design Optim., vol. 4, pp. 349-53, 2010.

[5] L. Lihong and L. Benli, "Research on the mechanism of abrasive particles accelerated and a cutting system of a premixed abrasive jet," Int. J. Plant Eng. Manag., vol. 2, pp. 200-6, 2010.

[6] H. Liu, J. Wang, N. Kelson, and R. Brown, "A study of abrasive waterjet characteristics by CFD simulation," Min. Process. Equip., vol. 69, pp. 488-93, 2004.

[7] I. Mihaltso, L. Tretiakova, and E. Nemet, Tremor Processes in Sewing Industry, vol. 2, Muszaki, Tekhnika, 1997, p. 214.

[8] I. Orlov and V. Dubrovyi, "Basics of technology and automatization heating of sewing details using," Light Ind., vol. 16, p. 232, 1994.

[9] K. Perepelkin, "Physical basics of describing and prognostication of textile materials. Modern state and practical significance," Nadezhnost, ekonomichnost $i$ kachestvo tekstilnykh materialov, vol. 1, pp. 3-7, 1998.

[10] V. Anokhin, "Polymers chemistry and physics-chemistry," Vushcha shkola, vol. 44, p. 399, 1997.

[11] B. Buzov, T. Modestova, and N. Alymenkova, "Material science of sewing industry," Lehprombytizdat, vol. 32, p. 424, 1996.

[12] H. Kukin, A. Solovev, and A. Kobliakov, "Textile material science," Lehprombytizdat, vol. 144, p. 352, 1999.

[13] E. Maltseva, "Material science of sewing industry," Light Food Ind., vol. 2, p. 232, 1993.

[14] M. Kazanskii, R. Lutsyk, and A. Melnikova, "Moisture effect of different forms connection on deforming dependences of polymeric materials," Izvestiia vuzov. Technol. Light Ind., vol. 3, pp. 31-6, 1997.

[15] L. Batai, T. Chen Min, and B. Kuzmichev, "Theoretic engagement of hydro-fil measurement method of textile materials," Izvestiia vuzov. Technol. Textile Ind., vol. 4, pp. 48-51, 2004.

[16] Y. Kuschevskii and J. Koshevko, "Factors classification of warmheating process use," Herald of Khmelnitskyi National University, vol. 1, pp. 5-8, 2008.

[17] Z. Romdhani, A. Baffoun, M. Hamdaoui, and S. Roudesli, "Drop impact on textile material: effect of fabric properties," Autex Res. J., vol. 14, no. 3, pp. 145-51, 2014, https://doi.org/10.2478/aut2014-0010.

[18] L. Hristian, D. L. Bordeianu, M. M. Ostafe, and G. Bőhm-Révész, "Creasing behavior of some woven materials made from combed 
yarns type," Annals of the University of Oradea: Fascicle of Textiles, Leatherwork, vol. XVIII, no. 2, pp. 47-52, 2017.

[19] M. S. Novaković, L. S. Putić, M. Bizjak, and S. B. Stanković, "Moisture management properties of plain knitted fabrics made of natural and regenerated cellulose fibres," Hemijska Industrija, vol. 69, no. 2, pp. 193-200, 2015, https://doi.org/10.2298/ HEMIND140201034N.

[20] E. Skrzetuska and J. Wojciechowski, "Investigation of the impact of environmental parameters on breath frequency measurement by a textile sensors," Sensor, vol. 20, no. 4, p. 1179, 2020, https:// doi.org/10.3390/s20041179.

[21] Y. Kuschevskii and L. Bukhantsova, "Hydro-mechanical method of textile materials forming," Herald of Khmelnitskyi National University, vol. 6, pp. 33-6, 2007.

[22] Y. Kuschevskii, J. Koshevko, and O. Yakymchuk, "Functional possibilities of using liquid-active work environment in forming headwear details," Herald of Kyiv National University of Technology and Design, vol. 5, no. 1, pp. 52-8, 2010. 